\title{
Laboreal
}

Volume $13 \mathrm{~N}^{\circ} 1$ | 2017

Varia

\section{Espaços de debate e poder de agir na construção da segurança das organizações}

Los espacios de debate y el poder de actuar en la construcción de la seguridad de las organizaciones

Les espaces de débat et le pouvoir d'agir dans la construction de la sécurité des organisations

Debate spaces and the power to act upon the construction of safety in the organisations

\section{Raoni Rocha}

\section{(2) OpenEdition}

\section{Journals}

Edição electrónica

URL: http://journals.openedition.org/laboreal/800

DOI: $10.4000 /$ laboreal.800

ISSN: 1646-5237

\section{Editora}

Universidade do Porto

\section{Refêrencia eletrónica}

Raoni Rocha, "Espaços de debate e poder de agir na construção da segurança das organizações ", Laboreal [Online], Volume $13 \mathrm{~N}^{0} 1$ | 2017, posto online no dia 01 julho 2017, consultado o 24 setembro 2020. URL : http://journals.openedition.org/laboreal/800 ; DOI : https://doi.org/10.4000/laboreal.800

\section{Este documento foi criado de forma automática no dia 24 setembro 2020.}

\section{(c) (7) \&}

Laboreal está licenciado com uma Licença Creative Commons - Atribuição-NãoComercial 4.0 Internacional. 


\section{Espaços de debate e poder de agir na construção da segurança das organizações}

Los espacios de debate y el poder de actuar en la construcción de la seguridad de las organizaciones

Les espaces de débat et le pouvoir d'agir dans la construction de la sécurité des organisations

Debate spaces and the power to act upon the construction of safety in the organisations

Raoni Rocha

\section{REFERÊNCIA}

Rocha, R. (2014). Du silence organisationnel au débat structuré sur le travail : les effets sur la sécurité et sur l'organisation. Thèse de doctorat préparée à l'École doctorale SP2 'Sociéte, Politique, Santé Publique', spécialité Ergonomie, Université de Bordeaux.

\section{NOTA DO EDITOR}

http://dx.doi.org/10.15667/laborealxiii0117rr

Manuscrito recebido em: dezembro/2016

Aceite após peritagem: março/2017

Júri da tese: Francisco Duarte (Presidente); François Daniellou (Orientador) e Vanina Mollo (Co-orientadora); Pierre Falzon e Benoît Journe (Arguentes). 


\section{Introdução}

1 Os modelos e ferramentas atuais de gestão de segurança nas empresas são antigos e se revelam, muitas vezes, ineficazes para garantir a segurança dos sistemas. Diferentes pesquisas destacam a importância em se reestabelecer o coletivo de trabalho, implantar práticas reflexivas entre os trabalhadores e se colocar em discussão o trabalho real (Daniellou, Simard, \& Boissières, 2010). Apesar disso, são limitadas as pesquisas que, de fato, conseguiram desenvolver espaços de debate sobre o trabalho real e não conhecemos muitas contribuições efetivas de uma abordagem como essa ou quais condições permitem o seu desenvolvimento. Assim, uma pesquisa de doutorado foi desenvolvida em uma empresa de distribuição de energia elétrica com um rígido sistema de controle e sanções nos casos de não respeito às regras. Essa pesquisa experimentou espaços de debate entre trabalhadores de diferentes escalóes. 0 objetivo deste resumo de tese é, assim, mostrar quais são as contribuições sistêmicas e as condições para o desenvolvimento de uma abordagem que busque fazer do debate sobre o trabalho uma ferramenta que possibilite o desenvolvimento de uma gestão de segurança eficaz.2. Do silêncio organizacional aos espaços de debate sobre o trabalho

O 'silêncio organizacional' aparece nas empresas quando 'a escolha dominante no interior de diversas organizações para os empregados é guardar para si próprios as suas opiniões e preocupações em relação aos problemas organizacionais' (Morrison \& Milliken, 2000, p. 707). Essa definição mostra que o silêncio do empregado é fruto de uma decisão deliberada, e que as informações omitidas podem se tornar críticas para o sistema. Duas razões desencorajam qualquer forma de expressão (Rocha, Mollo \& Daniellou, 2015): o medo de repercussões negativas e a percepção de uma frágil comunicação de informações a respeito do campo. $O$ indivíduo, temendo a forma com que os gestores ou seus pares receberão a mensagem, e estando convencido de que os seus chefes estão pouco dispostos a escutá-los ou a tratar alguns problemas do campo, não divulgam as informações, já que, de toda forma, ele pensa que isso não acarretará nenhum resultado prático (Dejours, 1998).

3 Com o intuito de romper o silêncio organizacional, Detchessahar (2001) desenvolve a "teoria dos espaços de discussão", preconizando a discussão em torno do trabalho, no plano da ação, de maneira regular e protegida, coordenada por um gestor, podendo ou não, em função do tema, ter relação hierárquica com os membros da equipe. A ideia de discussão sobre o trabalho não pode, entretanto, estar desassociada do poder de agir [1] dos participantes destes espaços no tratamento das situações discutidas. Essa reflexão evoca o princípio da subsidiariedade, que trabalha com as noções de "poder" e "autonomia" de grupos sociais. Esta noção define os princípios de distribuição do poder em uma comunidade e seu principal interesse é pensar, ao mesmo tempo, a liberdade e a autoridade dos indivíduos (Millon-Delsol, 1993). No mundo das empresas, o conceito de subsidiariedade se traduz pelo fato de que um escalão gerencial superior não deve exercer as funções que podem ser eficientemente realizadas por um escalão hierarquicamente inferior. Ao mesmo tempo, os níveis inferiores devem estar apoiados na coordenação entre as suas atividades e aquelas da organização sistêmica (Melé, 2005). O princípio da subsidiariedade nos remete assim à "pesquisa permanente do nível mais pertinente para a ação" (Petit, Dugué, \& Daniellou, 2011, p. 404) a partir da articulação e do ajustamento dos diferentes coletivos da organização. 


\section{Métodos de campo e da análise dos dados}

4 Com o objetivo de instaurar espaços de debate para gerir questões de segurança, uma pesquisa foi realizada numa empresa francesa de distribuição de energia elétrica. 0 objetivo principal da pesquisa foi desenvolver espaços de debate sobre o trabalho (EDT) interligados pelo princípio da subsidiariedade como forma de romper o silêncio organizacional. Para isso, dois comitês foram formados: um Comitê Científico, composto por 3 pesquisadores (o doutorando, junto ao seu orientador e coorientador); e um Comitê de Pilotagem, composto pelos 3 pesquisadores e 4 representantes da direção da empresa. Ambos os comitês mantinham um diálogo constante com o Comitê de Direção (Codir) da empresa, formado pelos membros de sua diretoria.

O método de coleta de dados dessa pesquisa se compõe de duas grandes fases: uma fase de experimentação dos EDT, tendo por objetivo o desenvolvimento do debate das situações de campo ligadas à segurança (com as subfases "análise do trabalho", "tratamento das situações de ação características - SAC" e "experimentação do dispositivo de debate"); e uma fase de perenização/ generalização dos EDT e de organização da subsidiariedade, relacionando os espaços de debate locais com os escalões superiores da empresa, onde foram realizadas formações e um acompanhamento das ações dos gestores em relação à implantação dos dispositivos de debate. Reuniões periódicas entre os comitês, assim como apresentações da pesquisa ao Codir tiveram lugar constantemente durante o desenvolvimento do projeto. A figura abaixo ilustra a metodologia empregada.

Figura 1: Metodologia da pesquisa

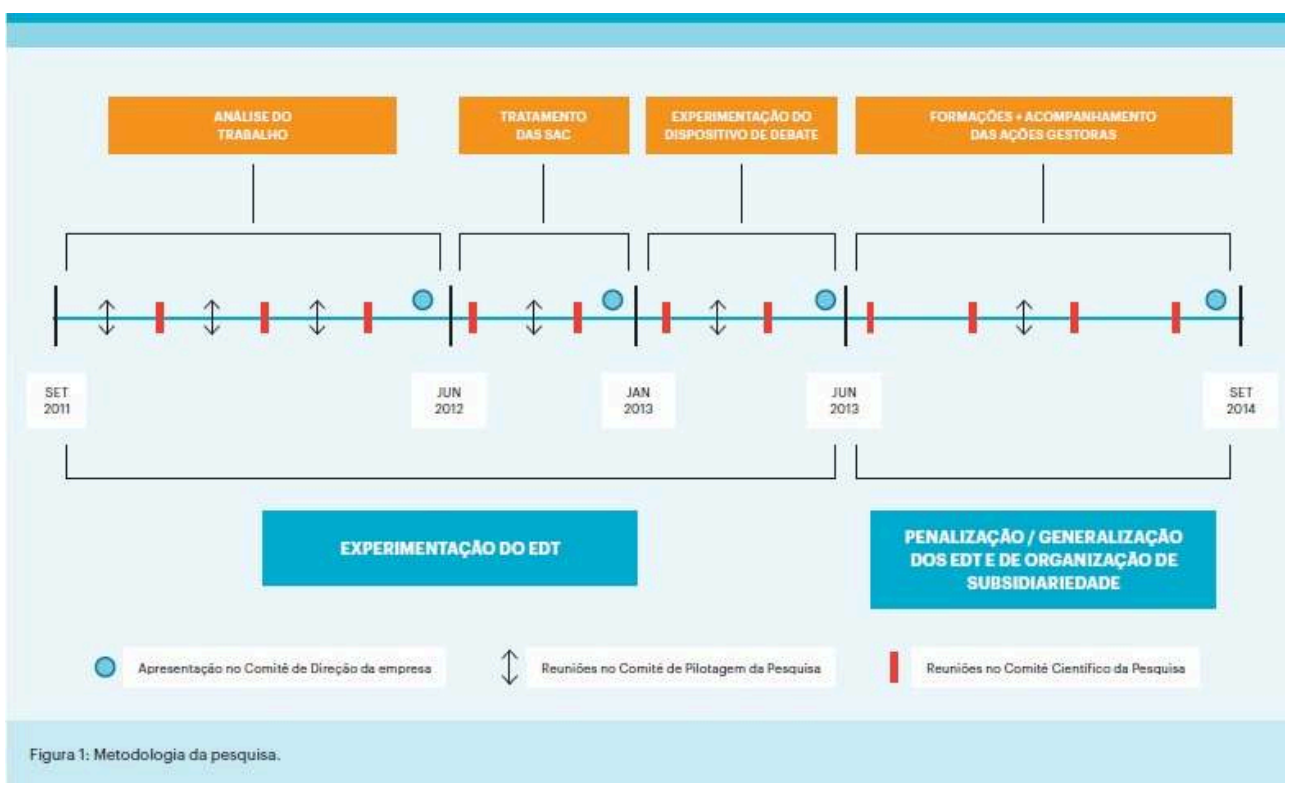

Foi realizada uma análise do conteúdo dos debates na unidade piloto: na subfase de tratamento das SAC e de experimentação do dispositivo de debate, as reuniões foram registradas e transcritas. 0 material transcrito foi analisado de maneira qualitativa (tratamento temático de acordo com as grandes variáveis do debate) e quantitativa, com o auxílio do Actogram Kronos (Kerguelen, 2003), software de tratamento de dados de observação cronológica das variáveis preestabelecidas. Os gráficos fornecidos por esse software permitiu obter uma "fotografia" da sessão completa, mostrando a 
evolução de todas as variáveis codificadas no mesmo gráfico, e também nos permitiu observar a variação dos dados entre as sessões registradas [ $\left.{ }^{2}\right]$.

\section{Resultados: a produção de um debate subsidiário}

Em quatro unidades da empresa foi coconstruído um sistema de declaração e tratamento das anomalias de campo, que permitiu o compartilhamento e tratamento local dessas anomalias. Esta tese concentrou-se sobre os resultados da unidade piloto. Neste local, foi implantado um dispositivo local de debate, no qual os eletricistas tiravam fotos de eventos significativos do campo; repassavam-nas ao supervisor no momento do debriefing; e, após a seleção do supervisor, as fotos passavam por um tratamento coletivo (figura abaixo).

Figura 2: Dispositivo local de debate sobre o trabalho

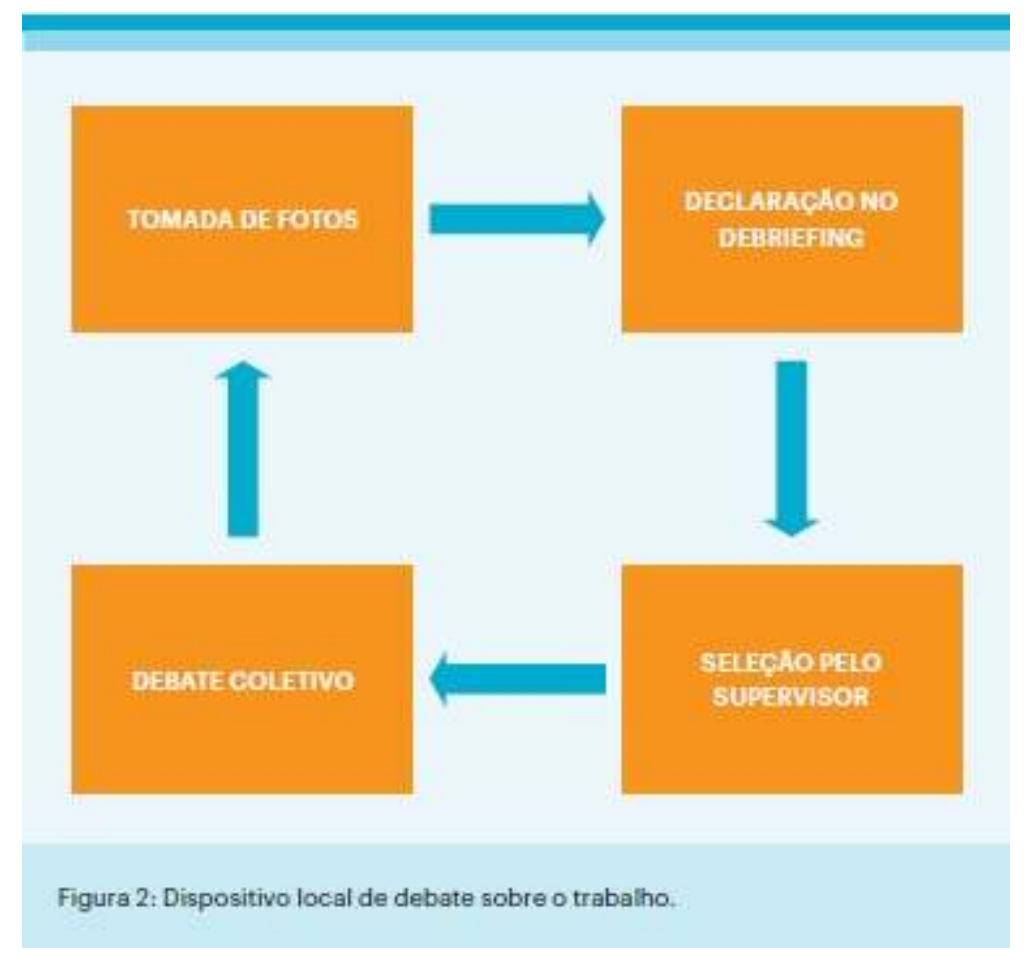

Esse dispositivo proporcionou um aumento da declaração e do tratamento de situações de risco; permitiu uma apropriação progressiva dos participantes, fazendo-os falarem cada vez mais sobre o trabalho; possibilitou uma aprendizagem mútua entre os eletricistas; e trouxe contribuições na construção da saúde e no desenvolvimento do coletivo local de trabalho (Rocha, Mollo e Daniellou, 2015).

9 Na medida em que o dispositivo local funcionava, percebeu-se que os trabalhadores possuíam condições de tratar localmente uma série das situações discutidas (fusíveis queimados, disjuntores danificados, ausência de parafusos ou fiação em alguns equipamentos, etc.). Apesar disso, esse dispositivo trouxe, também, algumas dificuldades, principalmente quando o grupo não tinha condições de tratar todas as situações discutidas. Existia, assim, a necessidade de declarar tais situações a outro nível que pudesse tratá-las. Partindo dessa ótica, foi decidido, em comum acordo com o setor de prevenção da empresa, envolvido no projeto desde o seu início, que as 
situações não tratadas na unidade piloto seriam, então, reportadas a ele através de reuniões mensais pelo Comitê Prevenção-Segurança (CPS). Se o setor da prevenção não tivesse recursos para tratar algumas situações, elas seriam remontadas até os diretores da empresa, durante as reuniões trimestrais do Codir, às quais o responsável da prevenção participa. A figura abaixo apresenta a evolução do dispositivo sistêmico construído junto aos diferentes trabalhadores e escalões da empresa.

Figura 3: Dispositivo de debate sistêmico sobre o trabalho.

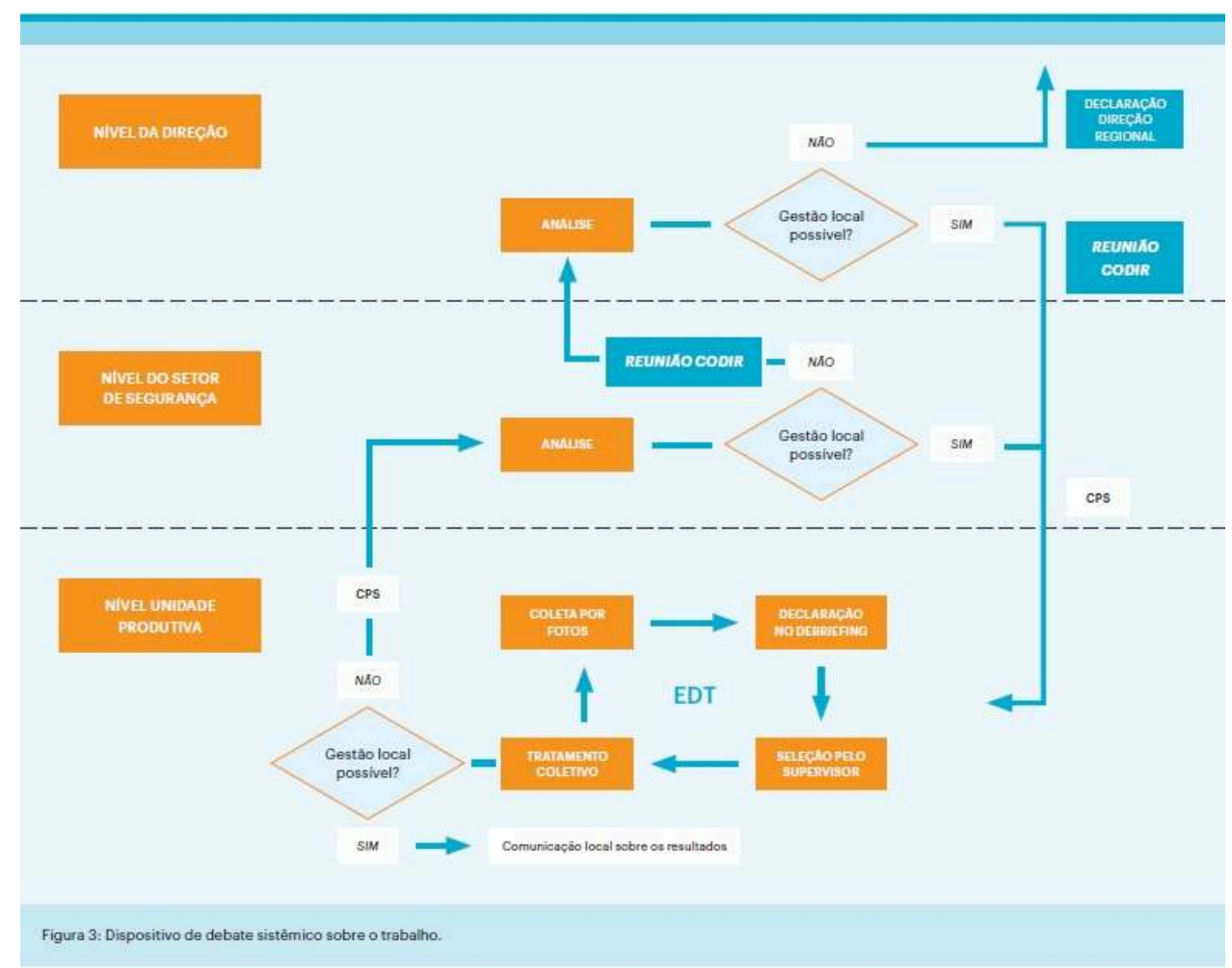

\section{Contribuições sistêmicas e condições do debate estruturado sobre o trabalho}

O desenvolvimento do debate local regido pelo princípio da subsidiariedade permitiu, primeiramente, o desenvolvimento da inovação na empresa. Como exemplo, um eletricista remonta uma situação de melhoria na bolsa de ferramentas, quando vê cair uma ferramenta desta bolsa, numa intervenção no alto de um poste. Este exemplo mostra não somente a ação do debate sobre a segurança, já que a modificação da bolsa evita acidentes potencialmente graves, mas gera, também, situações de inovação dos materiais anteriormente existentes. Em seguida, o debate sobre o trabalho pôde criar condições de reconexão da gestão da empresa com a realidade do trabalho, tanto ao supervisor da unidade piloto, como aos gestores de outros níveis hierárquicos. 0 supervisor coordena, sugere e confronta os pontos de vista. Ele acessa a realidade do trabalho dos eletricistas, as adaptações realizadas e as modalidades de tratamento das situações discutidas, possibilitando a sua reaproximação a uma realidade que não era anteriormente muito clara. Por fim, o debate estruturado sobre o trabalho permitiu uma antecipação de riscos e prevenção de acidentes por meio do desenvolvimento de uma 
dinâmica de aprendizagem cotidiana e de compartilhamento de conhecimento técnico entre os participantes. O compartilhamento e a gestão das situações vividas permitiu, em alguns momentos, aprender com o grupo e, em outros, ensiná-lo: "as coisas que discutimos aqui, eu nunca tinha visto na minha formação", "agora eu estou entendendo" e "eu não sabia" foram algumas das verbalizações exprimidas pelos eletricistas.

11 É possível, também, estabelecer algumas condições para que o debate sobre o trabalho estruturado pelo princípio da subsidiariedade se desenvolva.

Capacidade da Direção em questionar os próprios limites: se o espaço de debate evidencia a atividade real, ele permite, também, tornar visível as vulnerabilidades da empresa e as suas causas. Deste ponto de vista, a gestão pode não querer conhecer as suas vulnerabilidade e inibir essa prática. Aceitar escutar opiniões diferentes da sua, para que os erros e as infrações da prescrição possam ser expressos sem que a gestão use de seu poder coercitivo para interrompê-los é fundamental. A questão passa a ser, assim, a própria capacidade em conhecer a sua atividade e tratar as vulnerabilidades.

Um gestor que garanta e anime o debate local: o supervisor teve um papel central na efetividade dos espaços de debate. Ele era, ao mesmo tempo, o guarantor e o animador do debate, alocando sistematicamente uma parte das reuniões semanais para a discussão coletiva em torno das fotos remontadas. Ele fomentava o debate, organizava o tratamento das situações de risco discutidas e fazia a ponte entre as situações não tratadas localmente e o setor da prevenção da empresa. Por fim, ele comunicava sistematicamente o grupo sobre o tratamento das situações discutidas. Esse raciocínio pode ser estendido também aos gestores intermediários da empresa. Eles asseguraram tanto a articulação entre o conteúdo das situações trabalhadas nos diferentes níveis hierárquicos com os interlocutores de escalões superiores e inferiores, quanto o período de debate em parte de suas reuniões.

Um método coconstruído: os espaços de debate se submeteram a adaptações particulares a fim de responder às especificidades das unidades trabalhadas. Na unidade piloto, o debate foi feito por meio de fotos (em outras unidades ele foi realizado via vídeos ou relatos de casos), os casos eram reportados ao supervisor (em outras eram feitos aos gestores operacionais) e a composição dos grupos foi realizada com eletricistas e chefia direta (em outras a reunião se deu com a chefia indireta ou com trabalhadores de outros setores). 0 dispositivo sistêmico seguiu a mesma linha. Foi decidido, junto ao responsável da prevenção, que seria utilizada uma parte da reunião CPS. Em outras unidades, as situações não tratadas localmente eram reportadas diretamente aos gestores intermediários ou ao setor de recursos humanos. Essa coconstrução foi primordial, na medida em que ela permitiu integrar um novo método numa estrutura organizacional já existente, sem que houvesse o acréscimo de reuniões extras e, por consequência, sem um custo suplementar aos trabalhadores envolvidos no projeto.

Um debate baseado na confrontação com o real, com um coletivo regular e com possibilidade de ação: todo o processo de debate esteve sempre centrado no trabalho real dos sujeitos (aquilo que, de fato, eles fazem), intermediado por fotos de situações do campo. Esta é uma das condições fundamentais do debate: ele deve se centrar na atividade de trabalho. Para isso, deve ser sustentado por materiais de suporte, como fotos, vídeos ou relatos, para que não haja digressões em relação ao assunto central (por exemplo, sobre questões salariais). Ao mesmo tempo, o debate deve ser feito dentro de uma lógica de confrontação de ideias e com uma presença constante dos seus membros. Foi na confrontação dos saberes dos sujeitos regularmente presentes que observamos as 
situações mais ricas em termos de aprendizagem. Por fim, é necessário que os participantes tenham a possibilidade de agir sobre as situações discutidas. Caso contrário, como verbaliza um deles, "o debate sobre o trabalho certamente não terá vida longa se ficar só na retórica e não puder ser tratado".

Disponibilização de recursos aos níveis inferiores: é necessário que os participantes do debate tenham a possibilidade de agir sobre as situações discutidas. A cada situação que chegava ao setor de prevenção ou ao Codir, a reflexão construída não esteve somente no tratamento da situação, mas sobretudo sobre como oferecer recursos para que o nível inferior pudesse tratar tal situação. Quando o responsável pela prevenção se ocupa da modificação de uma regra para adaptá-la à realidade ou quando a Direção realiza um trabalho junto aos prestadores de serviço de forma a evitar a instalação de equipamentos que possam trazer problemas aos eletricistas, não é apenas a gestão dessas situações que está em jogo. Nesses casos, os trabalhadores locais ganham autonomia e poder de agir para desenvolver as suas ações frente a situações semelhantes no futuro. Assim, o objetivo do debate estruturado sobre o trabalho não é aumentar o número de situações reportadas aos outros níveis (e correr o risco de saturar as suas capacidades de tratamento), mas sim de reportar o mínimo possível, de forma que esse mínimo se torne o essencial e possa ter uma solução definitiva.

\section{Conclusão}

Essa pesquisa buscou desenvolver o debate sobre o trabalho, demonstrar as suas contribuições e refletir sobre as suas condições de implantação. $O$ desenvolvimento do debate estruturado sobre o trabalho, ou seja, a construção de espaços de debate organizados pelo princípio da subsidiariedade, possibilitou o acesso a essas problemáticas e o seu tratamento de maneira durável. Antigas cadeias de comando e linhas de comunicação verticais deram lugar à interação e à participação horizontal nas unidades envolvidas. $\mathrm{O}$ supervisor da unidade passou a atuar como um coordenador e não um controlador. Os indivíduos deixaram de ser isoladamente responsabilizados pelos problemas, pois o produto do debate passou a ser compartilhado. Dessa forma, o debate estruturado sobre o trabalho colocou em dúvida os métodos clássicos de gestão da segurança, baseados em uma gestão diretiva, afastada do campo e imersa numa excessiva produção de procedimentos de segurança. Desde que algumas condições sejam respeitadas, o debate e a sua articulação com os escalões hierárquicos podem permitir uma gestão cotidiana das situações perturbadas e sobrepujar o perímetro clássico da segurança para ir em direção a uma organização capaz de identificar, antecipar e gerir

BIBLIOGRAFIA

Clot, Y. (2010). Trabalho e poder de agir. Belo Horizonte: Fabrefactum. 
Daniellou, F., Simard, M., \& Boissières, I. (2010). Fatores Humanos e Organizacionais da Segurança Industrial. (Traduzido do original Facteurs humains et organisationnels de la sécurité industrielle por Rocha, R., Duarte, F., e Lima, F.). Toulouse: ICSI. Disponível no link: http://www.FonCSI.org/ fr/cahiers/

Dejours, C. (1998). Souffrance en France. La banalisation de l'injustice sociale. Paris : Seuil.

Detchessahar, M. (2001). Quand discuter, c'est produire... Pour une théorie de l'espace de discussion en situation de gestion. Revue française de gestion, 132, 32-43.

Kerguelen, A. (2003). Actogram Kronos pour Windows, Editions Octarès : Toulouse.

Melé, D. (2005). Exploring the Principle of Subsidiarity in Organisational Forms. Journal of Business Ethics, 60, 3, 293-305. https://doi.org/10.1007/s10551-005-0136-1

Millon-Delsol, C. (1993). Le Principe de subsidiarité, Paris, PUF (coll. « Que sais-je ? »).

Morisson, E., \& Miliken, F. (2000). Organizational Silence: a barrier to change and development in a pluralistic world. The Academy of Management Review, 25, 4, 706-725. https://doi.org/10.5465/ AMR.2000.3707697

Petit, J., Dugué, B., \& Daniellou, F. (2011). L'intervention ergonomique sur les risques psychosociaux dans les organizações : enjeux théoriques et méthodologiques. Le travail humain, $74,4,391-409$.

Rocha, R., Mollo, V., \& Daniellou, F. (2015). Work debate spaces: a tool for developing a participatory safety management. Applied Ergonomics, 46, 107-114. https://doi.org/10.1016/ j.apergo.2014.07.012

\section{NOTAS}

1. A expressão "poder de agir" é aqui usada como a capacidade que os trabalhadores têm em solucionar os problemas que aparecem para eles na situação de trabalho e, consequentemente, as condições fornecidas pela gestão para que isso seja possível. Esta definição está em consonância com a ressalva que faz Yves Clot (2010) em seu livro "Trabalho e poder de agir" (págs 14 e 15), alertando que "desde que as noções de potência de ação, poder de agir ou poderes da ação foram introduzidas no domínio da psicologia do trabalho (...), elas se tornaram objeto de múltiplos usos (...)" e que "essa diversidade é de grande interesse. Uma vez reconhecida, ela convida a uma discussão acirrada, tornada possível atualmente. Esse debate é também necessário por evitar, sem dúvida, que a expressão se torne somente um acesso fácil à ação".

2. Para mais detalhes sobre a metodologia, consultar: Rocha, R. (2014). Du silence organisationnel au débat structuré sur le travail: les effets sur la sécurité et sur l'organisation. Tese (Doutorado em Ergonomia) - Universidade de Bordeaux, Bordeaux. 


\section{AUTOR}

\section{RAONI ROCHA}

Engenharia de Saúde e Segurança

Universidade Federal de Itajubá, Campus Itabira, Rua Irmã Ivone Drumond, 200 - Distrito

Industrial II, Itabira - MG, CEP 35903-087 Brasil

raoni@unifei.edu.br 